\title{
$X$
}

\section{BALANÇO DA PRODUÇÃO SOBRE A PEDAGOGIA HISTÓRICO- CRÍTICA NOS EVENTOS E NA REVISTA DO HISTEDBR*}

\author{
Aline Letícia Trindade Rosa \\ Flávio Massami Martins Ruckstadter \\ Gabriela Aparecida de Assis \\ Vanessa Campos Mariano Ruckstadter
}

\section{Introdução}

Este capítulo é resultado de investigações realizadas por pesquisadores ligados ao Programa de Pós-Graduação em Educação - Mestrado Profissional em Educação Básica da Universidade Estadual do Norte do Paraná (PPEdUENP). Originou-se a partir de trabalhos apresentados inicialmente no I Seminário de Pesquisa do PPEd, evento realizado em novembro de 2019 e que congregou especialmente trabalhos desenvolvidos por pós-graduandos ligados ao programa. Além disso, o trabalho se insere em um projeto maior desenvolvido no âmbito das reflexões do Grupo de Estudos e Pesquisas: História, Sociedade e Educação no Brasil (GT HISTEDNOPR - Norte Pioneiro do Paraná), sediado no Campus de Jacarezinho da UENP.

Uma das linhas de pesquisa do grupo investiga a Pedagogia HistóricoCrítica (PHC) com a finalidade de subsidiar teórica e metodologicamente ações ligadas à produção científica sobre a Educação Básica. Esta tendência educacional brasileira foi elaborada por Dermeval Saviani entre fins dos anos de 1970 e ao longo da década de 1980 e se caracteriza como uma pedagogia com viés crítico/revolucionário desenvolvida a partir das críticas às pedagogias hegemônicas não-críticas (especialmente as pedagogias tradicional, escolanovista e 
tecnicista) e às pedagogias crítico-reprodutivistas (teoria da escola como aparelho ideológico de Estado, teoria da escola dualista e a teoria do sistema de ensino como violência simbólica) ${ }^{1}$. A PHC tem sua essência originalmente fundamentada no materialismo histórico-dialético, notadamente nos trabalhos de Karl Marx, Friedrich Engels e Antonio Gramsci, bem como na psicologia histórico-cultural a partir dos estudos de Lev Semionovich Vygotsky. Desse modo, a partir destas bases, a Pedagogia Histórico-Crítica concebe a educação como um trabalho que produz, "[...] direta e intencionalmente, em cada indivíduo singular, a humanidade que é produzida histórica e coletivamente pelo conjunto dos homens [...]." (SAVIANI, 2011, p. 13). Além disso, esta pedagogia considera a escola como espaço privilegiado para a socialização do saber sistemati zado; ela é lugar do conhecimento elaborado e não do conhecimento espontâneo. Em suma: a escola é o espaço da ciência.

Se inicialmente coube ao professor Dermeval Saviani a elaboração dos fundamentos da PHC, ao longo das quatro décadas que se seguiram, o desenvolvimento dessa tendência pedagógica se tornou resultado de contribuições coletivas. Isto se deu principalmente em torno do Grupo Nacional de Estudos e Pesquisas História, Sociedade e Educação no Brasil (HISTEDBR).

O HISTEDBR foi fundado por Saviani e outros pesquisadores da área da Educação na Universidade Estadual de Campinas (UNICAMP) em 1986. Com sua expansão nos anos seguintes, converteu-se em uma ampla rede de pesquisadores com Grupos de Trabalho (GTs) sediados por todos os Estados brasileiros em instituições de ensino superior públicas e privadas. Esta rede interinstitucional de pesquisadores tem desempenhado importante papel na história da educação brasileira, especialmente na defesa da escola pública e da democratização do ensino em todos os seus níveis e modalidades. Dentre as ações desenvolvidas pelo HISTEDBR, destacam-se os eventos acadêmicos promovidos pelo grupo (Jornadas e Seminários Nacionais).

Para nortear as discussões neste texto, questionou-se sobre a produção acadêmica acerca da Pedagogia Histórico-Crítica em três veículos de divul-

\footnotetext{
${ }^{1}$ A crítica às pedagogias hegemônicas (não-críticas) e às teorias crítico-reprodutivistas foi apresentada por Dermeval Saviani (2008) na obra "Escola e Democracia". O livro é uma das referências mais importantes na elaboração da PHC e atingiu em 2018 sua 43a edição.
} 
gação: anais dos eventos organizados pelo HISTEDBR (Jornadas e Seminários Nacionais) e na revista publicada pelo grupo, o periódico HISTEDBR online. Desse modo, procedeu-se a um levantamento de trabalhos com o propósito de elaborar uma síntese inicial que pudesse elucidar alguns dos caminhos investigativos na produção acadêmica sobre a PHC.

O percurso escolhido para realizar este trabalho foi o levantamento e análise bibliográfica do tipo estado do conhecimento ou estado da arte. Este tipo de trabalho de caráter bibliográfico tem o intuito de mapear e discutir uma certa produção acadêmica nos mais variados campos do conhecimento, a fim de evidenciar em que aspectos e espaços essas pesquisas, sejam elas, dissertações de mestrado, teses de doutorado, comunicações em anais de eventos entre outros, encontram-se e apresentam-se no meio acadêmico. Esse tipo de metodologia adotada tem caráter [...] inventariante e descritivo da produção acadêmica e científica sobre o tema que busca investigar, à luz de categorias e facetas que se caracterizam enquanto tais em cada trabalho e no conjunto deles, sob os quais o fenômeno passa a ser analisado. (FERREIRA, 2002, p. 1).

A principal finalidade deste trabalho inicial é nortear a pesquisa e compreender melhor o objeto de estudo dos trabalhos em andamento no Mestrado Profissional do PPEd ${ }^{2}$. Através desse levantamento, por exemplo, é possível analisar como a PHC vem sendo discutida atualmente, em quais campos e áreas do conhecimento ela se destaca, se ela direciona para determinados níveis e modalidades de ensino, entre outros fatores importantes que podem contribuir significativamente em nossos trabalhos.

Para atingir nossos objetivos neste texto, apresentamos uma discussão que está dividida em três partes: inicialmente, fazemos uma breve exposição dos critérios utilizados pelos autores no processo de seleção dos trabalhos nas bases de dados. Em seguida, apresentamos resultados das análises dos textos selecionados dos eventos e, por fim, na revista. Espera-se que do mesmo modo que este levantamento serve às nossas pesquisas, ele possa servir de

\footnotetext{
${ }^{2}$ Referimo-nos especificamente às investigações realizadas por Aline Letícia Trindade Rosa e Gabriela Aparecida de Assis, desenvolvidas sob a orientação de Flávio M. M. Ruckstadter e Vanessa C. M. Ruckstadter, respectivamente. Ambas as investigações pretendem desenvolver produtos educacionais fundamentados teórica e metodologicamente a partir da Pedagogia Histórico-Crítica.
} 
base para outras investigações e trabalhos comprometidos com a adoção de práticas pedagógicas contra-hegemônicas na Educação Básica brasileira na atualidade.

\section{Caminhos para a elaboração do estado da arte}

A primeira questão que nos colocamos foi sobre em quais bases de dados realizar um levantamento de trabalhos acadêmicos que versassem sobre a PHC. Tendo em vista a importância do HISTEDBR no cenário educacional e a repercussão nacional dos trabalhos desenvolvidos através de seus GTs regionais, consideramos que um bom ponto de partida poderia ser o levantamento nas publicações diretamente ligadas ao grupo. Por isso a escolha dos dois principais eventos realizados pelo grupo e do periódico organizado e mantido pelo mesmo.

Após a definição das bases de dados a serem consultadas, a etapa seguinte envolveu a definição de critérios para seleção de textos. Tanto nos eventos quanto na Revista HISTEDBR Online, os mesmos critérios foram respeitados, ainda que tratados de modo separado devido à organização de suas pla taformas online. Para seleção, buscamos pelo termo Pedagogia Histórico-Crítica em títulos e/ou resumos e/ou palavras-chave e/ou lista de referências.

Com relação aos eventos o primeiro passo foi localizar os arquivos. No site do HISTEDBR, (<http://www.histedbr.fe.unicamp.br/>) é possível acessar informações sobre como se dá a organização do Grupo bem como de seus acervos. No entanto, ao adentrar esses links de acesso às páginas dos eventos, encontramos páginas indisponíveis e/ou sem o anexo dos anais com os trabalhos publicados. Em especial, sobre as páginas das Jornadas, não foi possível ter acesso a nenhuma das edições, pois todas encontravam-se com erro, informando a seguinte mensagem "Not Found. The requested URL was not found on this server". No que se refere especificamente aos Seminários Nacionais, nas primeiras edições do evento, realizadas nos anos de 1992, 1993 e 1995, não há o link para acesso. Por sua vez, para os eventos realizados nos anos de 2001 e 2016, há os links de acesso porém, ao clicar, as páginas não são encontradas. 
Diante dessas dificuldades, passamos a buscar os anais dos eventos nas páginas das Universidades/Faculdades que organizaram e realizaram cada uma das edições do Seminário e das Jornadas. Com isso foi possível contemplar nesse levantamento grande parte dos anais.

Já com relação a Revista HISTEDBR Online, o acesso às bases de dados se deu através do endereço eletrônico: <https://periodicos.sbu.unicamp.br/ ojs/index.php/histedbr/about>, a fim de analisar: Artigos, Resenhas, Resumos e Debates, que apresentam a PHC como tema. A Revista HISTEDBR On-line é uma publicação trimestral do Grupo de Estudos e Pesquisas do HISTEDBR, que conta com 79 edições de Setembro de 2000 até o ano de 2019.

Considerando os critérios adotados, selecionamos 100 (cem) trabalhos para análise dos eventos do HISTEDBR, sendo 60 (sessenta) publicados nos Anais das Jornadas no período de 2002 a 2018 e 40 (quarenta) nos anais do Seminário Nacional, nos anos de 1997, 2003, 2006, 2009, 2016 e 2019. E com relação à Revista HISTEDBR Online foram selecionados 34 (trinta e quatro) trabaIhos que versam sobre a PHC, no período de dezenove anos de publicações.

Cabe informar que até este momento da pesquisa ainda não constam nos resultados os trabalhos de todas as edições das Jornadas e dos Seminários, devido a uma dificuldade em encontrar os arquivos das seguintes edições: I, IV e V Jornadas do HISTEDBR e os Seminários de 1991, 1992, 1995 e $2001^{3}$.

Ao concluir essa primeira etapa do processo do trabalho, a próxima refere-se a análise dos mesmos, sendo que a partir das leituras mais detalhadas sobre as pesquisas selecionadas, torna-se possível elencar categorias como forma de organizar e apresentar as ideias do trabalho de forma mais clara e plausível para o entendimento dos caminhos que permeiam os trabalhos sobre a PHC.

\section{Levantamento das produções acadêmicas nos eventos do Histedbr}

Após o levantamento dos textos nos Anais dos eventos disponíveis o material foi organizado considerando algumas categorias: Fundamentos Epis-

\footnotetext{
${ }^{3}$ Oportunamente, caso seja possível acessar tais arquivos, poderemos apresentar uma nova versão deste texto que contemple de modo mais amplo tais produções.
} 
temológicos; Níveis e Modalidades de Ensino; Áreas do Conhecimento; Formação docente; e Região. Essas categorias permitem a classificação e uma melhor visualização do resultado dos dados coletados. A seguir, apresenta-se a classificação dos trabalhos analisados divididos por suas categorias, feitas de forma comum entres os dois eventos selecionados.

A primeira categoria, denominada de "Fundamentos Epistemológicos" se refere aos trabalhos que tratam sobre a origem e a concepção da Pedagogia Histórico-Crítica, bem como discutem seus fundamentos filosóficos e métodos. Com relação a essa categoria, foram encontrados 42 trabalhos entre os anos de 2002 a 2019. Alguns trabalhos foram possíveis de serem identificados no próprio título, por exemplo aquele intitulado "A Pedagogia Histórico-Crítica e sua fundamentação", apresentado na XIV Jornada do HISTEDBR - 2017. Já outros, por sua vez, apenas foram identificados no resumo.

Na sequência, a categoria denominada "Níveis e Modalidades de Ensino" direcionou o levantamento para os trabalhos apresentados sobre a Pedagogia Histórico-Crítica que estão voltados para o trabalho pedagógico em determinadas fases e níveis do ensino na Educação Básica. A partir dessa categorização foram encontrados 20 trabalhos, assim podem ser subclassificados como: Ensino Médio (2); Ensino Médio Integrado (1); Anos finais do Ensino Fundamental (2); Educação Especial (3); Formação de docentes (magistério) (1); Educação Infantil (7); Educação do Campo (3); Educação de Jovens e Adultos, EJA (2); e Educação Básica no contexto geral (1). Essa última classificação "Educação Básica no contexto geral" se deu pelo fato de que o trabalho intitulado "Reflexões sobre a avaliação na perspectiva da Pedagogia Histórico-Crítica" traz uma análise a respeito da avaliação em toda a Educação Básica, principalmente nos níveis do Ensino Fundamental e Médio, sendo então necessária incluí-la de modo mais abrangente do que as demais.

As "Áreas de Conhecimento" são as grandes áreas do conhecimento: Ciências Exatas e da Terra; Ciências Biológicas; Engenharias; Ciências da Saúde; Ciências Agrárias; Ciências Sociais Aplicadas; Ciências Humanas e Linguísticas, Letras e Artes. Desse modo, foi a terceira categoria elencada para o inventário. De acordo com o levantamento dos trabalhos foram encontrados referentes às áreas do conhecimento 29 pesquisas, dentre as quais: Ciências da Saúde - Edu- 
cação Física (5); Ciências Exatas e da Terra - Matemática (5); Ciências Humanas - Geografia e História (6); Ciências Biológicas - Ciências (3) e Linguísticas, Letras e Artes - Português - Arte - Música (11).

Na categoria denominada "Formação Docente" seja ela na formação inicial ou continuada, foram encontrados 23 trabalhos voltados para essa discussão, como, por exemplo, o trabalho intitulado "Ideário pedagógico na formação de professores: análise a partir da Pedagogia Histórico-Crítica" da XII Jornada do HISTEDBR em 2014.

Os eventos do HISTEDBR a cada ano são sediados em diferentes Universidades/Faculdades em diferentes estados e regiões do Brasil. A partir do levantamento realizado podem ser mapeados os locais e regiões onde a pesquisa sobre a PHC tem maior ou menor frequência. Conforme o levantamento é possível classificar como Sudeste (43); Norte (5); Sul (42) e Nordeste (10).

\section{Levantamento preliminar das produções acadêmicas na revista HIS- TEDBR Online}

Assim, como a apresentação anterior sobre o levantamento das pesquisas sobre a PHC nos eventos, este estado da arte visa selecionar trabalhos sobre esse tema na Revista HISTEDBR Online, parte também do trabalho coletivo organizado pelo Grupo de estudo HISTEDNOPR entre professores e mestrandos. Os mesmos procedimentos e critérios para a busca e seleção dos trabalhos foram utilizados para essa Revista.

Dentre as 79 edições publicadas e disponíveis para a consulta, entre os períodos de Setembro/2020 até o ano de 2019, foram selecionados 34 trabaIhos sobre a PHC. Após a seleção dos trabalhos, procedemos à definição de categorias de análise, que permitissem identificar a forma como tais pesquisas têm abordado a PHC, para isto elencaram-se as seguintes categorias: Região; Níveis e Modalidades de Ensino; Áreas do Conhecimento; Formação Docente; e Referencial Teórico.

Quanto à categoria "Região", a principal finalidade era identificar onde se originam as pesquisas sobre a PHC, e com isso reconhecer as necessidades 
de pesquisa de cada região. Os resultados encontrados foram: Norte (1); Nordeste (2); Centro-Oeste (3); Sudeste (18); e Sul (9).

Sobre "Níveis e Modalidades de Ensino", procurou-se reconhecer como a PHC é abordada na Educação Básica, nos diferentes níveis e modalidades de ensino. O levantamento de dados identificou a presença de estudos sobre a PHC em vários níveis e modalidades de ensino, nas mais diversas perspectivas. Seguem os números de trabalhos encontrados: Educação Infantil (2); Ensino Fundamental Anos Finais (1); Ensino Médio (1); Educação Especial (1); Educação do Campo (2); Formação de Docentes (3); Educação Básica, no contexto geral (3), totalizando 13 trabalhos.

A respeito das Áreas do Conhecimento, foram mapeadas pesquisas considerando as grandes áreas, para que fosse possível organizar e compreender os campos de estudos que se interessam pela PHC. Tendo em vista o levantamento de dados e os trabalhos selecionados, apresenta-se a seguinte visão: Ciências da Saúde, Educação Física e Psicologia (6); Ciências Humanas, contemplando História e Geografia (5); Ciências Linguísticas, que envolvem as Letras e as Artes (1); Ciências Sociais, campo da Sociologia e assuntos sobre os diferentes Movimentos Sociais (4).

A categoria "Formação Docente" foi estabelecida em razão do considerável número de trabalhos científicos que abordam a $\mathrm{PHC}$ e suas contribuições ou implicações sobre a formação de docentes, seja inicial ou continuada. Dentre os trabalhos elencados, 18 estabelecem a relação entre a PHC e a formação de professores. Entre esses trabalhos, vale ressaltar a presença de apenas uma pesquisa que visa a formação de Gestores a partir da PHC.

Para a categoria "Referencial Teórico", procuramos identificar os três principais autores citados nos diversos textos como referenciais teóricos. Verificamos que Dermeval Saviani, João Luiz Gasparin e Newton Duarte são as principais referências. Vale ressaltar a presença de duas obras constantemente utilizadas entre os trabalhos analisados: Vigotski e o "aprender a prender": crítica às apropriações neoliberais e pós-modernas da teoria vigotskiana, (DUARTE, 2006) e Pedagogia histórico-crítica e luta de classes na educação escolar (SAVIANI; DUARTE, 2012). 
Durante o processo de levantamento de dados foi possível constatar o baixo número de publicações sobre a PHC na Revista HISTEDBR On-line no período de 2000 a 2011. Os poucos trabalhos publicados nesse período enfatizavam as contribuições e discussões sobre a PHC em diferentes áreas do conhecimento. Importante ressaltar que, entre esses materiais levantados no referido período, nenhum abordou a formação de professores. Considerando a escassez dessa interface, ressalta-se a importância do desenvolvimento de pesquisas sobre a contribuição da PHC para a pesquisa sobre formação de professores. Somente a partir da edição de número 45 da Revista HISTEDBR On-line, no ano de 2012, a PHC aparece com mais frequência e com mais intensidade no campo da Formação Docente, além das demais áreas do conhecimento.

A realização desse levantamento possibilitou compreender a necessidade de partir das publicações de resultados de pesquisas já realizadas a partir da PHC para o preparo e desenvolvimento de um trabalho completo, no caso a dissertação, com um olhar amplo em relação ao "[...] comprometimento com o ensino de qualidade, com a aprendizagem efetiva e com o enraizamento pedagógico alicerçado, consolidado, engajado e comprometido com a formação da classe trabalhadora, tendo neste ideal alfa e ômega da pedagogia históricocrítica. (MARSIGLIA; MARTINS; LAVOURA, 2019, p.23). Portanto, o estudo em questão, além de apresentar novos conceitos, novos autores e obras sobre a PHC, amplia a percepção da necessidade de maior desenvolvimento de pesquisas a partir dela no campo educacional, com o objetivo de motivar e instruir diferentes instâncias educacionais e sociais.

\section{Conclusão}

O principal objetivo deste texto foi apresentar o mapeamento preliminar da produção acadêmica sobre a Pedagogia Histórico-Crítica nos eventos e na revista do grupo no qual essa teoria se originou. A tarefa coletiva em um dos GTs do grupo, o HISTEDNOPR, intentou colaborar com as pesquisas em andamento desenvolvidas no grupo e destacar a importância de levantamentos para dialogar com a produção acadêmica já existente na área de Educação. 
Percebe-se que a maioria dos trabalhos mapeados nos eventos promovidos pelo HISTEDBR são referentes ao debate epistemológico e aos fundamentos da PHC. De um total de 100 trabalhos selecionados, 42 se dedicaram à discussão dos fundamentos teóricos da PHC. Já aqueles que se dedicam a analisar as práticas docentes a partir da $\mathrm{PHC}$ nos diferentes níveis e modalidades somam 20. Isso pode direcionar a uma hipótese: a de que a didática para a Pedagogia Histórico-Crítica está em construção, e é uma tarefa coletiva que necessita ampliação e divulgação. Nem todo professor da Educação Básica, por exemplo, pode ter a oportunidade de formalizar e divulgar sua prática docente na PHC e compartilhar os resultados de sua experiência. Também pode indicar a necessidade do compromisso coletivo na construção de uma didática para a PHC em cada uma das áreas do conhecimento. Sobre isso, percebe-se um número maior de pesquisas divulgadas nos eventos de trabalhos que relatam experiências a partir da PHC na área de Linguísticas, Letras e Artes - Português - Arte - Música (11 trabalhos). Já na revista, há duas áreas com número próximo de publicações: Ciências da Saúde, Educação Física e Psicologia (6 trabalhos) e Ciências Humanas, contemplando História (1 trabalho) e Geografia (4 trabalhos).

Especificamente sobre o aspecto da necessidade coletiva de construção de uma didática para a Pedagogia Histórico-Crítica é fundamental destacar as possibilidades que se abrem com a difusão dos Mestrados Profissionais em Educação. No caso da UENP, com o mestrado que tem a Educação Básica como área de concentração, isso se torna ainda mais significativo, pois um dos objetivos do curso é articular Educação Básica e Ensino Superior a partir da formação de um professor pesquisador, que investigue problemas que são originários de sua prática profissional. Desse modo, os produtos que serão desenvolvidos pelos mestrandos no programa poderão contribuir nessa tarefa coletiva de elaboração de uma didática para a PHC, ou seja, para esta que é uma das mais importantes pedagogias contra-hegemônicas brasileiras na atualidade.

No que se refere aos trabalhos sobre formação docente, há um número crescente de artigos na revista. Foram 23 trabalhos apresentados nos eventos e 18 artigos publicados na revista, o que soma um total de 41 trabalhos so- 
bre a PHC na formação de professores, um deles, tendo como centro a PHC na formação de gestores.

Tanto nos eventos quanto na Revista percebe-se a predominância de pesquisas sobre PHC desenvolvidas na região sudeste, seguida da região Sul, o que leva a pensar sobre a própria história nacional em relação às políticas de pós-graduação e apoio ao desenvolvimento de pesquisas no país.

Ao finalizar o levantamento das produções acadêmicas dos trabalhos acerca da Pedagogia Histórico-Crítica nos eventos e na revista organizados pelo HISTEDBR é possível destacar a importância e a necessidade desse tipo de inventário para que se tome como ponto de partida para a pesquisa o conhecimento já produzido e divulgado anteriormente sobre a temática, já guardadas as devidas dificuldades no acesso a todos os trabalhos, bem como os limites desse tipo de levantamento, que deve ser coletivamente e constantemente (re) construído.

\section{Referências}

DUARTE, N. Vigotski e o "aprender a aprender": crítica às apropriações neoliberais e pós-modernas da teoria vigotskiana. 4. Ed. Campinas: Autores Associados, 2006.

FERREIRA, Norma Sandra de Almeida. As pesquisas denominadas "Estado da Arte". Educação \& Sociedade, ano XXIII, no. 79, agosto, 2002. Disponível em: < https://www.fe.unicamp.br/alle/textos/NSAF-AsPesquisasDenominadasEstadodaArte.pdf>. Acesso em: 26 Out. 2019

HISTEDBR. Disponível em: http://www.histedbr.fe.unicamp.br/index.html. Acesso em: 5 Out. 2019.

MACHADO, M. C. G. et. al. A Revista Histedbr on-line e suas contribuições à história da educação brasileira (2001 a 2015). In: Coutinho, Luciana Cristina 
SALVATTI et al. (Orgs.). História e historiografia da educação: debates e contribuições. Uberlândia: Navegando Publicações, 2018, p. 207-229.

MARSIGLIA, A. C. G. A prática pedagógica histórico-crítica na educação infantil e ensino fundamental. Campinas, SP: Autores associados, 2011. (Coleção educação contemporânea).

MARSIGLIA, Ana Carolina Galvão; MARTINS, Lígia Márcia; LAVOURA, Tiago Nicola. Rumo à outra didática histórico-crítica: superando imediatismos, logicismos formais e outros reducionismos do método dialético. Rev. HISTEDBR Online, Campinas, SP v.19, p. 1-28, 2019.

REVISTA HISTEDBR ON-LINE. Disponível em: https://periodicos.sbu.unicamp.br/ojs/index.php/histedbr/index. Acesso em: 5 Out. 2019.

SAVIANI, D. Escola e Democracia. Edição Comemorativa. Campinas: Autores Associados, 2008. (Coleção Educação Contemporânea).

SAVIANI, D. Pedagogia Histórico-Crítica: primeiras aproximações. 11a ed. Campinas: Autores Associados, 2011.

SAVIANI, D.; DUARTE, N. Pedagogia histórico-crítica e luta de classes na educação escolar. Campinas: Autores Associados, 2012. 